\title{
Effect of Spirituality Based Intervention on Domestic
}

\section{Violence Survivors}

\author{
Ms. Anjali Sahai ${ }^{1 *}$, Dr. Ritu Sharma ${ }^{2}$
}

\section{ABSTRACT}

Spirituality is considered culturally competent therapeutic intervention for domestic violence survivors. Limited number of studies have specifically emphasized at their experiences and needs. Women with abusive life partners use various strategies to cope, deal and heal from the physical and psychological violence. It is reported that their belief in a higher power is integral to their healing. Thus to study the role of spirituality as a tool for healing among domestic violence survivors, a sample of 50 married women who survived domestic violence were examined. For this purpose, the Revised Conflict Tactics scale (CTS-2; Straus, Hamby, Boney-McCoy \& Sugarman, 1996); Daily Spiritual experiences Scale (DSE; Underwood \&Teresi, 2002) and Beck Depression Inventory for depressive symptoms were used. Results indicate significant role of spirituality in healing women survivors. The majority reported that spirituality or God was a source of strength or comfort for them. Extent of spiritual involvement indicated increased psychological well-being and decreased depression.

Keywords: Spirituality; Domestic violence; Physical and Psychological violence.

Over forty percent Indian women are reported to be a victim of domestic violence. As found in India's third national family health survey (NFHS-III) report which is almost half of the population. Violence in the domestic area is usually perpetrated by males who are, or who have been, in positions of trust and intimacy and power. They could be husbands, boyfriends, fathers, fathers-in-law, brothers, uncles, sons, or other relatives.

Domestic violence affects the physical and mental health of females and is proven in every society in the world. According to the World Health Organization, globally 29\% to 62\% of women have experienced physical or sexual violence by an intimate partner. The United Nations defines violence against women as "any act of gender-based violence that results in, or is likely

\footnotetext{
${ }^{1}$ Assistant Professor Amity University, Uttar Pradesh

${ }^{2}$ Assistant Professor Amity University, Uttar Pradesh

*Responding Author

(C) 2016 I A Sahai, R Sharma; licensee IJIP. This is an Open Access Research distributed under the terms of the Creative Commons Attribution License (http://creativecommons.org/licenses/by/2.0), which permits unrestricted use, distribution, and reproduction in any Medium, provided the original work is properly cited.
} 
to result in, physical, sexual or mental harm or suffering to women, including threats of such acts, coercion or arbitrary deprivation of liberty, whether occurring in public or in private life."

Domestic violence in most cases is committed by men against women. Women can also be violent, but their actions account for a small percentage of domestic violence. Thus is context to atrocities against women they need to be empowered through education, employment opportunities, legal literacy, and right to inheritance. According to WHO (World Health Organization) research violence against women is undoubtedly a universal problem but there are regional patterns in its prevalence. It finds that women in Africa are almost twice as likely to experience violence than women in Europe - a particularly striking finding given that 'women' are defined in the study as females aged 15 and over suggests that there are regional patterns in its prevalence. It finds that women in Africa are almost twice as likely to experience violence as women in Europe.

There is now a growing awareness and re-awakening in healthcare, and in particular rehabilitation, to authentically distinguish between the science of curing disease and the spiritual practice of healing persons. The healing paradigm offers a model which focuses on those aspects of the person which must be addressed.

\section{Factors contributing to Domestic violence}

Some of the major factors that are attributable to domestic violence are lower levels of education or illiteracy; experience or witness to family violence in past; antisocial personality disorder; alcoholism or use of drugs; multiple partners or suspected by their partners of infidelity; stereotype thinking about female gender. Myths about family honor; false belief about male sexual entitlement and weak legal sanctions for psychological violence. The unequal position of women relative to men and the normative use of violence to resolve conflict are strongly associated with both intimate partner violence and non-partner sexual violence.

\section{Impact on Women's Physical and Mental health}

Domestic violence includes wide range of physical injuries like cuts, bruises, broken bones, chronic injuries like hearing loss, headaches, joint ache and permanent disability.

Its impact on women's mental health is even more severe than on physical health. The psychological damage caused by violence lasts longer and sometimes forever. The experience of violence affects women's self-esteem and makes them even more vulnerable to a variety of mental health problems including depression anxiety, phobia, post-traumatic stress disorder, suicide, suicide attempts and substance abuse.

\section{Impact of Domestic violence on Children}

Domestic violence seriously threatens the health and emotional wellbeing of children. In recent years, researchers have focused attention on children who are exposed to domestic violence. It is 


\section{Effect of Spirituality Based Intervention on Domestic Violence Survivors}

reported that Children who grow up in families where there is violence may suffer plethora of behavioral and emotional disturbances. It can also lead to committing violence or experiencing violence later in life. Domestic violence has also been associated with higher rates of infant and child mortality and morbidity.

Winter et al.,( 1999) examined how domestic violence on children may differ depending on a number of variables, such as their age, the nature and severity of the violence, the existence of other risk factors in their lives (i.e. Poverty, parental substance abuse).In general, childhood exposure to domestic violence can be associated with increased display of aggressive behavior, increased emotional problems such as depression and/or anxiety, lower levels of social competence, and poorer academic functioning in present as well later in life.

According to United Nations Development Programme (2005), nearly 70percent of married women between the age of 15 and 49 years face domestic violence in India.

\section{Traces of Domestic violence in India}

The first in-depth analysis of the status of women in India was undertaken in 1971, when the Government of India appointed a committee on the status of women in India (CSWI) to examine the rights and status of women within the changing socio-economic conditions of the country.

Most of the researches done bySakhare, (1985); Kishwar, (1986); Devi Prasad \&Vijayalakshmi, (1988);Kumari, (1989);Sinha,(1989);Saroja and Chandrika,( 1991);Paul,(1992) emphasized that reasons for domestic violence was majorly issues related withdowry.

Visaria (2000) did a study ina village of Gujarat and came to conclusion that $66 \%$ of women reported some form of psychological physical or sexual abuse or physical violence.

Subramanian et al. (2007) took a sample of 92,000 Indian households where domestic violence was reported by women. Results indicated that women who were victims of domestic violence have a $37 \%$ increased risk of suffering from the common respiratory condition. Women who had not experienced domestic violence themselves but had witnessed such acts against other female members in the same household were at an increased risk of developing Asthma by $21 \%$ in comparison to women who lived in violence free environment.

Hanes and Flannery (2000) have identified how abused women are 'active learners in their own lives”. Women try to learn from their own life experiences as best they can.

In one of the research done by Giesbrecht \& Sevcik (2000) reported that many survivors of domestic violence identified spirituality and their identity within their faith community as integral components of their identity and experience. Thus, the women viewed both their 
experience of abuse and recovery from abuse as occurring within the context of their faith. Many women as a result of it turned to their religious communities for support.

\section{Spirituality}

Spirituality has come to represent individual's efforts at reaching an existential goal in life. This could be finding meaning in one's life, wholeness, inner potential or interconnectedness with others.

Spirituality may act as a catalyst to protect domestic violence survivors from adverse outcomes. It has been found to have a positive impact on people experiencing crises and traumas such as divorce, physical or mental illness, substance abuse, sexual assault, and grief.

In one of the study of the influence of spirituality on mental health an inverse relationship between four dimensions of spirituality - meaning of life, intrinsic values, belief in transcendence and spiritual community - and symptoms of depression was reported.

Spirituality is often used interchangeably with religiosity though some researchers differentiate and according to Derezotes, (1995) religiosity, in contrast to spirituality, typically includes institutional affiliations that share a system of beliefs, rituals, and behaviors. Hill et al., (2003) suggest that spirituality and religiosity are related rather than independent constructs and that prayer overlaps in the conceptualization of both spirituality and religiosity.

Many studies investigated the relationship between well-being measure, spirituality and spiritual experience and findings were that people who have had spiritual experiences are in the normal range of well-being and have a tendency to report more extreme positive feelings than others.

In a qualitative study done by Hassouneh-Phillips (2003) reported spirituality as a dynamic coping mechanism but also as vulnerable in case of a sample of American Muslim female survivors of domestic violence.

Krishna Mohan (1999) looked into the effects of spiritual experiences of 200respondents belong to various spiritual organizations based on Hindu Philosophy. The findings revealed that after the spiritual experiences they were generally happy, cheerful and at peace, and rarely downhearted or depressed. Majority of the respondents reported having excellent health, and were satisfied with the meaning and purpose they found in their lives.

It is also reported that $72 \%$ percent women indicate the role of spirituality in their personal lives and $62 \%$ percent that spirituality was very important in their professional lives.

Due to the positive impact on coping and mental health, spirituality has become an increasingly popular area. However, the definition of spirituality continues to be a challenge for researchers, 
as evidenced by a variety of definitions in the literature. Some common definitions include: the search for meaning or purpose in life; faith in, or relationship with, a Higher Power and a transcendent dimension of the secular world; as well as sacredness of life, material values, altruism, idealism, awareness of the tragic, and the fruits of spirituality.

Various researches indicate that Spirituality appears to be an important factor in many helping practitioners' work although they did not used any uniform process to incorporate spiritual beliefs or principals into practice.

There are some researches which are contrary to the above findings conclude that it is highly inappropriate to direct clients, who seek help, to change their viewpoints about spirituality or religion.

\section{Spirituality and Domestic Violence}

Spirituality emerged as a factor in dealing with work stress, providing an additional source of support for some, though not all. Counselors presented a range of beliefs and practices and these were, in turn, influenced by a complex blend of work and personal experiences. Further, counselors' beliefs influenced their work in a variety of ways, by providing a motivation or coping strategies or support, or by giving them a framework in which to place clients' experiences.

Kreidler (1995) has identified the need for and usefulness of spiritual healing groups for those who are survivors of family violence. She argues that the experience of being hurt by someone one believes should love, cherish, and protect one cause a great deal of spiritual distress. This distress can manifest itself in various ways, including feelings of despair, belief that life is meaningless, or perceptions of oneself as powerless.

\section{METHOD}

Sample

Sample consisted of 50 women who were survivors of domestic violence. The criteria for being accepted into the study included those who were above 22 years of age and not more than 35 years, who had experienced physical and psychological aggression.

\section{Intervention}

The study sample participated in a Standard 10-week Spiritual Healing Program that was facilitated by experienced Psychologists working in this area. The program consisted of daily sessions that lasted for 2 hour each week. It included didactic instruction on Spirituality and its relationship to stress and health and group discussion on the same. 


\section{Procedure}

Women were selected from Noida region who wanted to voluntarily share their experience. They were receiving counseling and guidance in terms of their future endeavors. They were explained the purpose of the study, and asked if they would be willing to participate in a study investigating women's responses to domestic violence. It was further explained that participating or refusing to participate was unrelated to, and would have no bearing on the counseling they were receiving.

\section{Tools used}

Following tools were used for the current study:

Physical and Psychological Aggression. The Revised Conflict Tactics Scale (CTS-2;

Straus, Hamby, Boney-McCoy, \& Sugarman, 1996), the most widely used measure for assessing marital violence, was used to assess levels of physical assault, physical injury, sexual assault, and psychological aggression experienced by the female. The CTS-2 is a78-item scale that asks about the relationship conflict behaviors of the respondent and the respondent's partner. Five subscales make up the CTS-2: Negotiation, Psychological Aggression, Physical Assault, Sexual and Injury. The subscales used for this study have been found to have good internal consistency (According to Straus et al., 1996, internal consistency of CTS-2 subscales are Psychological Aggression _ .79; Physical Assault_. .86; Sexual_ . .87; Injury _.95)

Spirituality. Spirituality was assessed using the Daily Spiritual Experiences Scale(DSE; Underwood \&Teresi, 2002). The DSE is a 16-item scale that measures aspects of day-to-day spiritual experiences. The first 15 items are scored using a 6-point scale (i.e., 1_many times a day, 2_every day, 3_most days, 4_somendays, 5_once in a while, and 6_never or almost never). The 16th item (i.e., have four response categories: not close at all, somewhat close, very close, as close as possible).It was scored in such a manner that higher scores reflect higher daily Spiritual experiences). Scores could range from 16 to94. High internal consistency is reported for the scale, with alphas ranging from .94 to .95 .

Depression. The Beck Depression Inventory (BDI; Beck, Steer, \& Garbin, 1988;Beck et al., 1961) was used to assess depressive symptoms. The BDI contains 21 items with scores ranging from 0 (low depression) to 3 (maximum depression) for each item. Total BDI scores between 14 and 20 are indicative of moderate depression and scores above 21 indicates severe depression. The BDI has been found to have good reliability, with a split-half reliability coefficient of .86, and a test-retest reliability coefficient of .75 (Beck et al., 1988).

\section{Analysis}

Pre and Post Study were done to examine the effect of Spirituality on Physical and Psychological Aggression and Depression. 
Pre-Study data was analyzed to see the relationship between different dimensions of CTS-2 scale (i.e., Physical Assault Victimization; Psychological Aggression; Sexual Coercion; Physical Assault Perpetration; Injury) and Depression by using Beck’s Depression inventory.

\section{RESULT}

Table -1, Pre- Intervention Mean and Standard Deviation on the Revised Conflict Tactics Scale (CTS-2)\& Depression

\begin{tabular}{|l|l|l|}
\hline MEASURES Assault & MEAN & SD \\
\hline $\begin{array}{l}\text { Physical } \\
\text { Victimization }\end{array}$ & 13.23 \\
\hline Psychological Aggression & 23.92 & 13.88 \\
\hline Sexual Coercion & 12.59 & 11.54 \\
\hline Physical Assault Perpetration & 8.92 & 9.01 \\
\hline Injury & 8.74 & 9.26 \\
\hline Depression (BDI) & 19.92 & 13.35 \\
\hline
\end{tabular}

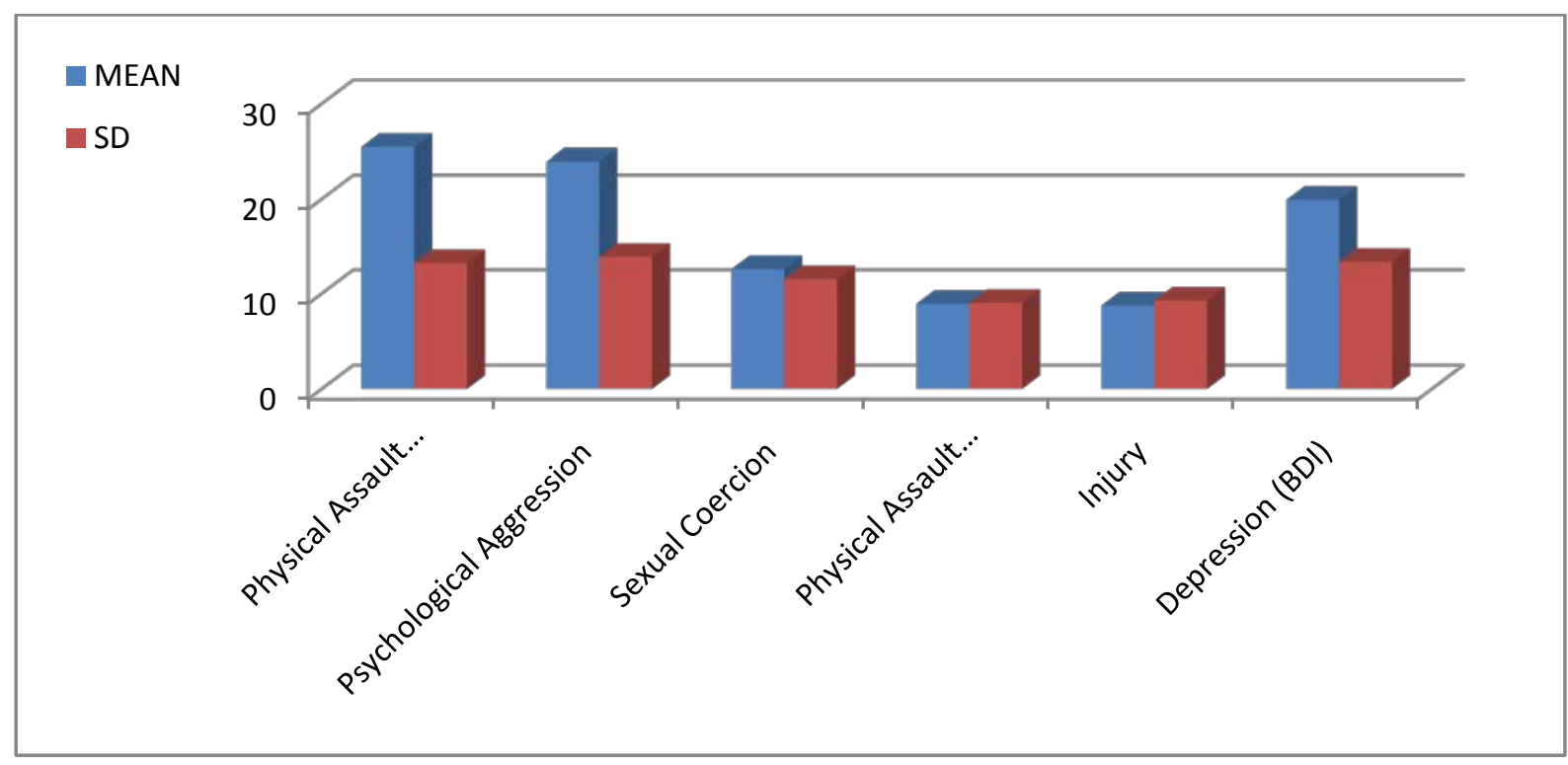

Figure 1.The mean and standard deviation of subscales of the Revised Conflict Tactics Scale (CTS-2)\& Depression

Post study was done using Spirituality as an intervention and its impact on Depression among domestic violence survivors. 
Table - 2Post- Intervention Mean and Standard deviation on Daily Spiritual Experiences \& Depression

\begin{tabular}{|l|l|l|}
\hline MEASURES & MEAN & SD \\
\hline Daily Spiritual Experiences (DSE) & 74.45 & 11.37 \\
\hline Depression (BDI) & 13.25 & 10.30 \\
\hline & & \\
\hline
\end{tabular}

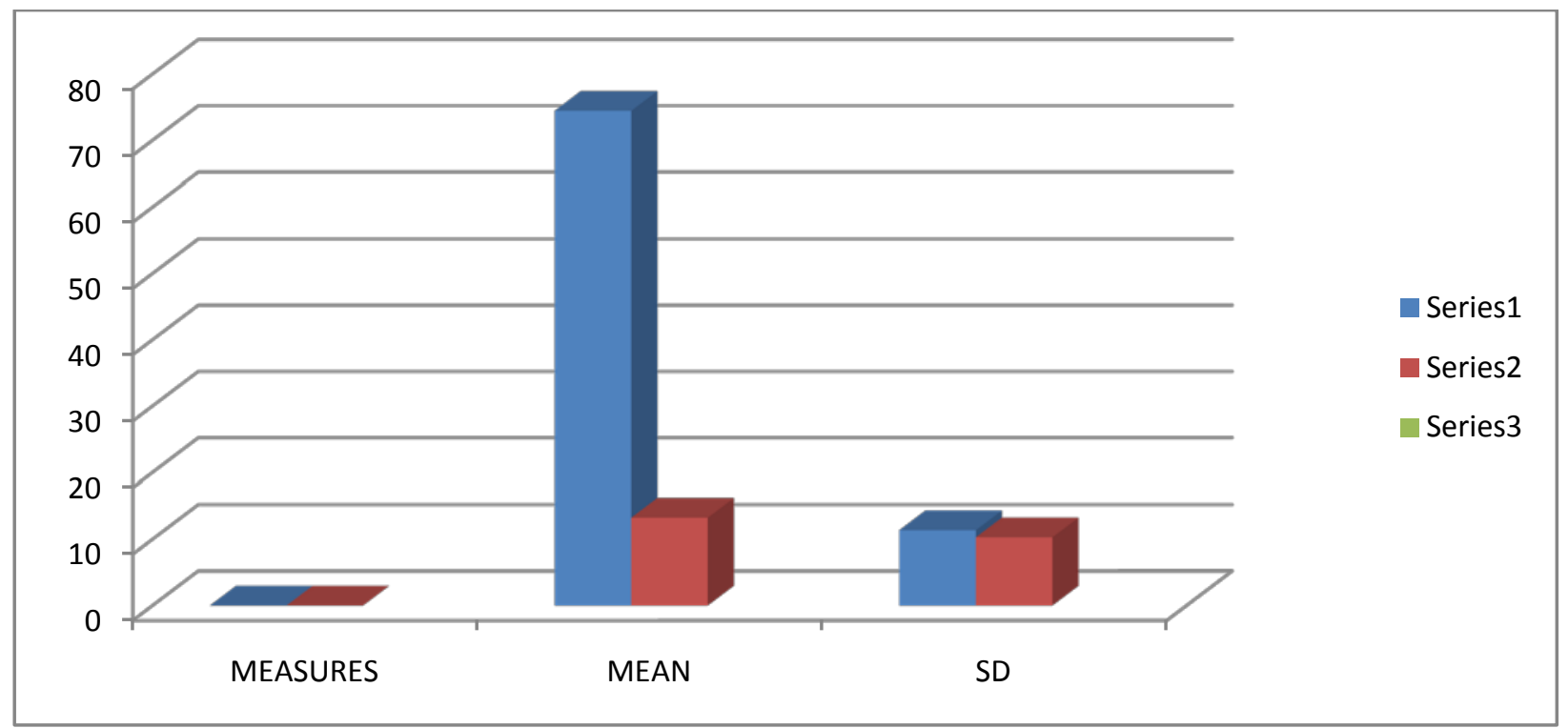

Figure 2. The Mean and Standard deviation on Daily Spiritual Experiences \& Depression Post intervention.

Table 3.The difference in Depression Pre and Post Intervention

\begin{tabular}{|l|l|} 
Depression & $\mathrm{t}$ - value \\
\cline { 2 - 2 } & $2.13^{*}$ \\
\hline
\end{tabular}

t-value is significant at 0.05 levels thus establishing the role of Spirituality among Domestic violence survivors.

\section{DISCUSSION}

The present study sought to examine ways in which Domestic violence impacts depression and the role of spirituality as an intervention. Results indicate that women who reported higher levels of spirituality had fewer depressive symptoms.

Pre and post study was done to see the impact of Spirituality as an intervention among domestic violence survivors. As Table 1 indicates mean and standard deviation on various sub scales of the revised Conflict Tactics Scale (CTS-2) and Depression. Depression is found to be at higher level Pre-intervention. Table 2 reflects data post intervention and depression is lower due to spirituality as an intervention (figure 2.) 
Table 3 indicates t- value to be significant at 0.05 levels thus validating the association between spirituality and depression. The overwhelming majority of women in the sample noted that spirituality or God was a source of strength or comfort for them. Spirituality acted as a source of coping mechanism for them to overcome the physical and mental trauma they had to go through as it assists them to come to terms with the problem. Having a strong spiritual outlook may help to find meaning in life's difficult circumstances. The spiritual practice of recognizing the interconnectedness of all life can also help buffer the pain that comes with difficult experiences. Thus the role of Spiritual Healing Program impacted in a positive manner in the life of domestic violence survivors. They responded positively and this was evident in their depression level which went down remarkably due to the intervention program.

Tameka L. Gillum et al., (2006) did a study and reported that inclusion of a voluntary spirituality component in victim service programs benefitted battered women. It resulted in lowering the level of depression that women in shelter tend to experience as they have to stay in a shelter environment.

Some researches have also emphasized that there are other factors apart from spiritual that leads to lowering the level of depression and boosts self-concept of women. It has been found in studies that the women's number of children was significantly correlated with both self-esteem and depression. The greater the number of children they had, the greater their self-esteem and the lower their level of depression. Thus, survivors of domestic violence, who are in abusive relationships are not receiving positive reinforcement from their intimate relationships but psychological satisfaction from their responsibilities as mothers and the closeness of their relationships with their children.

\section{LIMITATIONS OF THE STUDY}

Few limitations in the present study are worth addressing. Firstly, the sample size in the study is relatively small. It is possible that significant associations between the Spirituality and Depression outcomes were due to the small sample size.

Secondly, Sample for this study. Nearly all the sample was drawn from population seeking help. This may not reflect the population of domestic violence survivors as a whole. It is likely; they differ from community samples in the frequency and severity of abuse and social support.

Thirdly, the quantitative nature of the study sets limitation for women from speaking and defining the variables for themselves.

\section{IMPLICATIONS}

There are some potential implications that make this study an important contribution. Spiritual healing as a therapeutic intervention for domestic violence survivors has emerged as an 


\section{Effect of Spirituality Based Intervention on Domestic Violence Survivors}

important coping mechanism. This can be further researched and refined to minimize the physical and psychological effects of violence.

It can also provide guidelines for clinical training, practice and well-being.

A 2015 journal article on domestic violence in India, by Claire Snell-Rood, a medical anthropologist at the Department of Behavioural Science with the University of Kentucky, reported that 75-86 percent of women do not disclose that they are victims of abuse by their families. Thus to help them come out from this kind of mindset, awareness about spirituality and its impact on the self-concept, self-esteem and eventually on the wellbeing need to be emphasized and which is possible through initiatives and studies in this area of research.

\section{REFERENCES}

Andrews, F., \& Witey, S. (1976). Social indicators of well-being: Americans' perceptions of life quality. New York: Plenum.

Beasler, E. J., Derlega, V. J., Winstead, B. A., \& Barbee, A. (2003). Prayer as interpersonal coping in the lives of mothers with HIV. Women \& Therapy

Bhatti, R. and George, T. S. (2001). The measurement of family violence. Indian Journal of Social Work, 62(3), pp. 347-366

Bogat, G. A., Chin, R., Sabbath, W., \& Schwartz, C. (1983).The adult's social support questionnaire(Tech. Rep. 2). East Lansing: Michigan State University.

Brodsky, A. E. (2000). The role of religion in the lives of resilient, urban, African American single mothers. Journal of Community Psychology,28, 199-219.

Brome, D. R., Owens, M. D., Allen, K., \& Vevaina, T. (2000).An examination of spirituality among African American women in recovery from substance abuse. Journal of Black Psychology, 26, 470-486.

Brome, D. R., Owens, M. D., Allen, K., \&Vevaina, T. (2000).An examination of spirituality among AfricanAmerican women in recovery from substance abuse. Journal of Black Psychology,26, 470-486

Coker, A.L., Smith, P.H., Thompson, M.P., McKeown, R.E., Bethea, L., \& Davis, K.E. (2002). Social support protects against the negative effects of partner violence on mental health. Journal of Women's Health and Gender-Based Medicine, 11, 465- 475.

Connors, G.J., Tonigan, J.S., \& Miller, W.R. (1996). A measure of religious background and behavior for use in behavior change research. Psychology of Addictive Behaviors, 10(2), 90-96.

Connors, G.J., Tonigan, J.S., \&Miller, W.R. (1996). Ameasure of religious background and behavior for use in behavior change research. Psychology of Addictive Behaviors, 10(2), 90-96.

Corrigan, P., McCorkle, B., Schell, B., \& Kidder, K. (2003).Religion and spirituality in the lives of people with serious mental illness. Community Mental Health Journal, 39, 487-499.

Corrigan, P., McCorkle, B., Schell, B., \& Kidder, K. (2003).Religion and spirituality in the lives of people with serious mental illness. Community Mental Health Journal, 39, 487-499. 
Cunradi, C., Caetano, R., Clark, C., \& Shafer, J. (1999). Alcohol-related problems and intimate partner violence among White, African American, and Hispanic couples in the U.S. Alcoholism: Clinical and Experimental Research, 23, 1492-1501.

Dabir, N. (2003). A space for survivors of violence - Study off amily counseling centres and short stay homes in Maharashtra. Mumbai: Centre for Research and Violence Against Women, TISS

Department of Women and Child Development (2001).National Policy for Empowerment of Women 2001. New Delhi: Government of India, Ministry of Human Resource Development

Devi Prasad, B. (1990). Dowry related violence towards women: A sociological perspective. In S, Sood (Ed.), Violence Against Women (pp. 293-310). Jaipur, India: Arihant Publishers

Drescher, K.D., \& Foy, D.W. (1995). Spirituality and trauma treatment: Suggestions for including spirituality as a coping resource. National Center for PTSD Clinical Quarterly, 5, 4-5.

Dunbar, D., \&J eannechild, N. (1996).The stories and strength of women who leave battering relationships. Journal of Couples Therapy, 6, 149-173.

Ellison, C.G. (1998). Religion, health and well-being among African Americans. African American Research Perspectives, 4, 65-84

Ellsberg M, Jansen HA, Heise L, Watts CH, Garcia-Moreno C: Intimate partner violence and women's physical and mental health in the WHO multi-country study on women's health and domestic violence: an observational study. Lancet 2008,371(9619):1165-1172.

Fagan, J. (1996). The criminalization of domestic violence: Promises and limits. Washington, DC:U.S. Department of Justice.

Garcia-Moreno C, Jansen HA, Ellsberg M, Heise L, Watts CH: Prevalence of intimate partner violence: findings from the WHO multi-country study on women's health and domestic violence. Lancet 2006,368 (9543):1260-1269. Journal of Community Psychology, 28, 199-219.

George LK, Larson DB, Koenig HG, and McCullough ME: Spirituality and health: What we know, what we need to know. Journal of Social and Clinical Psychology.2000, 19: 102-116.

Journal of Women's Health and Gender-Based Medicine, 11, 465- 475.

Kishwar, M. (1986).Dowry - To ensure her happiness or to disinherit her? Manushi, 34, pp. 14-20

Miller WR, Thoresen CE: Spirituality and health. In Miller WR(ed),Integrating Spirituality Into Treatment: Resources for Practitioners. Washington, DC: American Psychological Association, 1999, 318.

Sakhare, S. (1985).Analytical study of 1200 suspicious deaths of newly married women in Vidarbha region of Maharashtra state in India. Nagpur: Seema Sakhare

Saroja, K. and Chandrika, S. N. (1991). Income and dowry: Some revealing connections. The Indian Journal ofSocial Work, 52(2), pp. 205-213.

Vindhya, U., Kiranmayi, A., Vijayalakshmi, V. (2001, October 27). Women in psychological distress. Evidence from of a hospital-based study. Economic and Political Weekly, Special Issue on Women's Studies.

Visaria, L. (2000). Violence against women - A field study. Economic and Political Weekly, No. 20, pp. 1742-1751. 